\title{
Magnetic Resonance Imaging of Vertebral Erosion in Spondyloarthritis
}

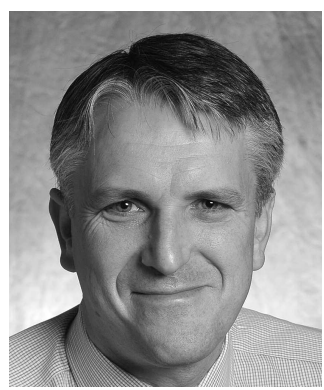

The association between ankylosing spondylitis (AS) and vertebral body erosion is long established. While originally thought of as a purely osteoproliferative condition leading to ankylosis, radiographic evidence of discovertebral destruction was first reported by Andersson ${ }^{1}$, and later the presence of erosion at the perimeter of the vertebral body was described by Romanus and Yden ${ }^{2}$. The stated intention of the latter publication was to "reexamine films taken at an earlier date, and previously interpreted as normal, so that we could study the very earliest stage of a syndesmophyte." The authors then describe "very slight signs of a superficial destructive process on the vertebral bodies. This initial stage is followed by calcification, ... and by ossification and structural alteration the typical syndesmophyte is formed." Some interesting things are noteworthy from this early work: (1) Romanus and Yden were the first to describe the presence of erosion at the anterior corners of the vertebral body - a feature that is now widely known as the Romanus lesion on radiography in most radiology and rheumatology textbooks ${ }^{3,4}$. (2) They were also the first to describe the sclerotic reaction that causes the vertebra to "shine in the original x-ray film." This feature has since been termed the "shiny corner" or "ivory corner"; although, somewhat confusingly, it is also but less often known as a "Romanus lesion." (3) These authors were observing the sequence of radiographic events by which a syndesmophyte may be formed. They worked backwards, selecting a population of patients with syndesmophytosis, and were seeking to describe the diagnostic features of ankylosing spondylitis before the stage of calcification and ossification so as to enable earlier accurate diagnosis. So it has been clearly stated from the first publication that the presence of erosion at the corner of a vertebral body may predate syndesmophyte formation with serial radiographic proof of this process; and that the erosion is transient and will be replaced by ossification, which will progress to a stage where "there is nothing in the vertebral bodies' shape or structure to suggest the preceding destructive phase."2

While the association between AS and radiographic evidence of spinal erosion is now well established, less is known about magnetic resonance imaging (MRI) of spinal erosion. Many illustrations of spinal erosion on MRI have been published, but little systematic research into MRI erosion has been performed, and correlation between MRI erosion and histopathology is almost nonexistent for the spine. The definition of erosion on MRI is challenging, with no international agreement on a precise definition and often no MRI definition included in the methodology of MRI observational research. In clinical practice the optimal MRI sequences for evaluation of spinal erosion are seldom used for several reasons, and usually spinal erosion is evaluated on T1 and T2 weighted sequences or short-tau inversion recovery (STIR), which offer many benefits for the evaluation of other processes but less so for erosion. In 2009, the Canada-Denmark International MRI Working group developed standardized definitions in both text and illustration for inflammatory and structural damage lesions in the spine and then validated these definitions in an attempt to improve consistency in this complex field of research ${ }^{5,6,7,8}$. This was followed by an alternate proposal for definitions of lesions and grading ${ }^{9}$ and then the Assessment of Spondyloarthritis International Society (ASAS)/ OMERACT MRI study group published a set of definitions with cross reference to the Canada-Denmark definitions ${ }^{10}$. Still, the intrinsic limitations of MRI for the evaluation of erosion are hard to avoid with inferior spatial resolution compared to computed tomography (CT) and only indirect ability to distinguish mineralized bone (Figure 1).

In this issue of The Journal, Baraliakos, et al ${ }^{11}$ investigate the significance of vertebral erosions as identified by MRI and the relationship of erosion to inflammation and changes in appearance following therapy. The authors conclude "it seems that spinal erosions are unlikely to significantly contribute to the main imaging outcome in studies in AS," with the implication that MRI outcomes focusing on bone marrow edema or osteitis need not include erosion as part of a scoring system for inflammation. This concurs with general opinion on the subject. Scoring of

See Erosions on spinal MRI in AS, page 1891

Personal non-commercial use only. The Journal of Rheumatology Copyright () 2013. All rights reserved. 


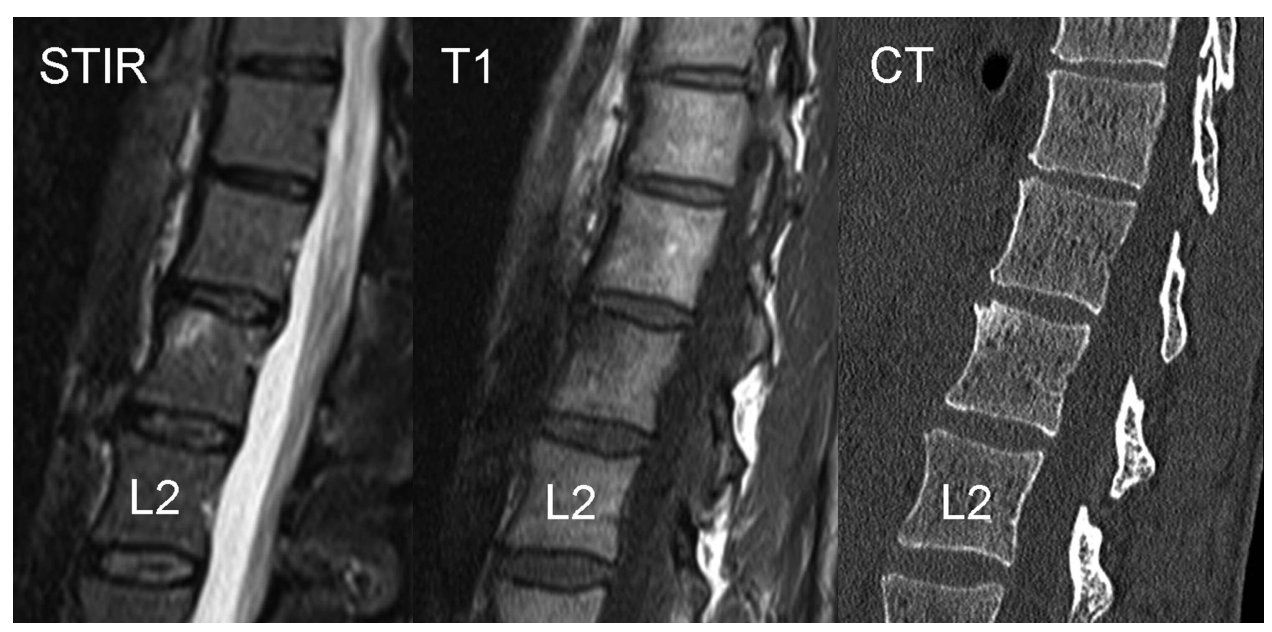

Figure 1. Three sagittal images of short-tau inversion recovery (STIR)-weighted magnetic resonance imaging (MRI), T1-weighted MRI, and computed tomography of the lumbar spine in a 37-year-old-male patient with ankylosing spondylitis. The STIR image shows a corner inflammatory lesion ${ }^{5}$ in the anterosuperior corner of the first lumbar vertebra with bone marrow edema (BME) causing increased signal (bright on STIR). The BME does not quite extend into the corner, which has been eroded. The definition of erosion requires the loss of overlying cortex, and while this can be appreciated on the T1-weighted image, the erosion is most easily seen on computed tomography (CT). The CT scan reveals not only the "Romanus lesion" but also a "shiny corner" due to vertebral sclerosis and a tiny adjacent syndesmophyte - precisely as described by Romanus in $1952^{2}$. Note that the syndesmophyte cannot be seen on the MRI scan.

inflammation without erosion is well known to be more feasible and more reliable. A multireader reliability exercise $^{12}$, showed that MRI inflammation scoring was significantly more reliable if erosion was not included (Spondyloarthritis Research Consortium of Canada, or Berlin system $)^{13,14}$ compared to when erosion is included in the scoring [ASspiMRI-a (AS spine MRI-acute)] ${ }^{15}$. The Berlin and ASspiMRI-a systems are identical, apart from the inclusion of the erosion score, so that any difference in reliability between these 2 systems can be directly attributed to the evaluation of erosion. Knowing that scoring of erosion in the spine can be problematic, it is therefore surprising that this project was performed with a single reader, contrary to generally accepted recommendations that the analysis of MRI observational data be conducted using either mean or concordant data from 2 trained expert readers.

Erosion at baseline did not correlate with most other variables in this study but did correlate moderately well with mobility (Bath AS Mobility Index), the importance of which is unclear. A lack of correlation with mobility after 2 years of anti-tumor necrosis factor (anti-TNF) therapy was noted, raising further doubt about the value of erosion scoring. However this could still be meaningful. If new bone formed as erosion scores declined, then subjects with more erosion could become more ankylosed and one might observe an inverse relationship between change in erosion score and change in mobility. As a sign of structural damage, it always was counterintuitive to think that erosion would contribute much to measures of disease activity. On the other hand, the presence, distribution, and extent of spinal erosion on MRI could be of considerable importance in triaging patients and identifying certain subjects that are predisposed to earlier, faster, or more extensive structural damage, i.e., ankylosis. There are no prospective data to support this but as MRI technology improves and research into structural damage evolves, it may yet be that erosion has an important role to play. The presence of erosion may not tell us much about disease activity, but as we already know that the presence of a syndesmophyte is a predictor of damage progression ${ }^{16}$, and if erosion predicts syndesmophytosis, then spinal erosion could turn out to be an earlier predictor of the same outcome. It has been shown that resolution of inflammation with anti-TNF therapy may be associated with development of new syndesmophytes ${ }^{17,18,19,20}$, and so it may be reasonably expected that an accelerated osteoproliferative phase would include the disappearance of erosion, as suggested in this article. Whether this progresses to ankylosis remains to be seen.

One challenge for future research is variability in the use of terminology between publications, which can be quite confusing for readers. For example this research group previously defined the discovertebral unit (DVU) with clarity ${ }^{15}$ and now have shortened the same definition to vertebral unit (VU). There are $23 \mathrm{VU}$ in the normal spine and, with a scoring range for each $\mathrm{VU}$ of $0-3$, this gives the Berlin score a range of $0-63^{14}$. While this is quite logical, the subjects in this project each had $46 \mathrm{VU}$ ! [A total of 22 patients $(\mathrm{n}=1012 \mathrm{VU})$ had MRI at both baseline and the 2-year followup.] This was achieved by counting the VU at each level twice - separately for anterior and posterior halves of the vertebral unit. The variation in definition in VU between inflammation scoring and erosion scoring

Personal non-commercial use only. The Journal of Rheumatology Copyright $@$ $~ 2013$. All rights reserved. 
should be made more explicit, and while the results are likely still valid, the reader will find it harder to understand when this is not clear. A different example is variation in the use of the word "Romanus" in so many different settings that often one can't be sure what it means. Transliteration between imaging modalities increases the likelihood of misunderstanding, especially that between radiography and MRI. Romanus lesions on radiography (erosion or sclerosis) are relatively specific for AS. The term "Romanus" has more lately been used for any MRI lesion in the corner of a vertebra, which should be studiously avoided, or else every degenerate spine will have a "Romanus inflammatory lesion" or "Romanus fat lesion," and the value of the expression will be lost. "Romanus" should be reserved for the vertebral body corner changes seen on radiography as described by Romanus, or not used at all.

In summary, MRI evaluation of bone marrow inflammation is well established, but research into MRI of structural damage is still at a preliminary stage. While erosion scoring may have little value in assessment of active disease, it may yet be an important part of structural damage assessment, diagnosis, and prognosis. While evidence for this is indeed scarce, we should remember that the very first report of vertebral corner erosion in spondyloarthritis was as a precursor of syndesmophytosis with self-evident diagnostic and prognostic significance ${ }^{2}$.

\author{
ROBERT G.W. LAMBERT, $M B$ BCh, FRCR, FRCPC, \\ Professor and Chair, \\ Department of Radiology and Diagnostic Imaging, \\ Walter C. Mackenzie Health Sciences Centre, \\ University of Alberta Hospital, \\ 8440 - 112 Street, \\ Edmonton, Alberta T6G 2B7
}

Address correspondence to Dr. Lambert; E-mail: rlambert@ualberta.ca

\section{REFERENCES}

1. Andersson O. Rontgenbilden vid spondyloarthritis ankylopoetica. Nord Med Tidskr 1937;14:2000.

2. Romanus R, Yden S. Destructive and ossifying spondylitic changes in rheumatoid ankylosing spondylitis (pelvo-spondylitis ossificans). Acta Orthop Scand 1952;22:88-99.

3. Firestein G, Budd R, Gabriel S, McInnes I, O’Dell J. Kelly's textbook of rheumatology, 9th ed. Philadelphia: Elsevier; 2013.

4. Resnick D. Diagnosis of bone and joint disorders, 4th Ed. Philadelphia: WB Saunders; 2002.

5. Lambert RG, Pedersen SJ, Maksymowych WP, Chiowchanwisawakit P, Ostergaard M. Active inflammatory lesions detected by magnetic resonance imaging in the spine of patients with spondyloarthritis - definitions, assessment system, and reference image set. J Rheumatol 2009;36 Suppl 84:3-17.

6. Ostergaard M, Maksymowych WP, Pedersen SJ, Chiowchanwisawakit P, Lambert RG. Structural lesions detected by magnetic resonance imaging in the spine of patients with spondyloarthritis - definitions, assessment system, and reference image set. J Rheumatol 2009;36 Suppl 84:18-34.

7. Pedersen SJ, Ostergaard M, Chiowchanwisawakit P, Lambert RG, Maksymowych WP. Validation of definitions for active inflammatory lesions detected by magnetic resonance imaging in the spine of patients with spondyloarthritis. J Rheumatol 2009;36 Suppl 84:35-8.

8. Chiowchanwisawakit P, Ostergaard M, Pedersen SJ, Lambert RG, Conner-Spady B, Maksymowych WP. Validation of definitions for structural lesions detected by magnetic resonance imaging in the spine of patients with spondyloarthritis. J Rheumatol 2009;36 Suppl 84:39-47.

9. Madsen KB, Jurik AG. MRI grading method for active and chronic spinal changes in spondyloarthritis. Clin Radiol 2010;65:6-14.

10. Hermann KG, Baraliakos X, van der Heijde DM, Jurik AG, Landewé R, Marzo-Ortega H, et al. Descriptions of spinal MRI lesions and definition of a positive MRI of the spine in axial spondyloarthritis: a consensual approach by the ASAS/OMERACT MRI study group. Ann Rheum Dis 2012;71:1278-88.

11. Baraliakos X, Listing J, Haibel H, Sieper J, Braun J. Vertebral erosions associated with spinal inflammation in patients with ankylosing spondylitis as identified by magnetic resonance imaging and the changes observed after 2 years of anti-TNF therapy. J Rheumatol 2013;40:1891-6.

12. Lukas C, Braun J, van der Heijde D, Hermann KG, Rudwaleit M, Østergaard M, et al. Scoring inflammatory activity of the spine by magnetic resonance imaging in ankylosing spondylitis: A multi-reader experiment. J Rheumatol 2007;34:862-70.

13. Maksymowych WP, Inman RD, Salonen D, Dhillon SS, Krishnananthan R, Stone M, et al. Spondyloarthritis Research Consortium of Canada magnetic resonance imaging index for assessment of spinal inflammation in ankylosing spondylitis. Arthritis Rheum 2005;53:502-9.

14. Haibel H, Rudwaleit M, Brandt HC, Grozdanovic Z, Listing J, Kupper H, et al. Adalimumab reduces spinal symptoms in active ankylosing spondylitis: Clinical and magnetic resonance imaging results of a fifty-two-week open-label trial. Arthritis Rheum 2006;54:678-81.

15. Braun J, Baraliakos X, Golder W, Brandt J, Rudwaleit M, Listing J, et al. Magnetic resonance imaging examinations of the spine in patients with ankylosing spondylitis, before and after successful therapy with infliximab: evaluation of a new scoring system. Arthritis Rheum 2003;48:1126-36.

16. Baraliakos X, Listing J, von der Recke A, Braun J. The natural course of radiographic progression in ankylosing spondylitis evidence for major individual variations in a large proportion of patients. J Rheumatol 2009;36:997-1002.

17. Maksymowych WP, Chiowchanwisawakit P, Clare T, Pedersen SJ, Østergaard M, Lambert RG. Inflammatory lesions of the spine on MRI predict the development of new syndesmophytes in ankylosing spondylitis: evidence of a relationship between inflammation and new bone formation. Arthritis Rheum 2009;60:93-102.

18. Chiowchanwisawakit P, Lambert RGW, Conner-Spady B, Maksymowych WP. Focal fat lesions at vertebral corners on magnetic resonance imaging predict the development of new syndesmophytes in ankylosing spondylitis. Arthritis Rheum 2011;63:2215-25.

19. Pedersen SJ, Chiowchanwisawakit P, Lambert RG, Østergaard M, Maksymowych WP. Resolution of inflammation following treatment of ankylosing spondylitis is associated with new bone formation. J Rheumatol 2011;38:1349-54.

20. Pedersen SJ, Sørensen IJ, Lambert RG, Hermann KG, Garnero P, Johansen JS, et al. Radiographic progression is associated with resolution of systemic inflammation in patients with axial spondyloarthritis treated with TNF $\alpha$ inhibitors. A study of radiographic progression, MRI inflammation and circulating biomarkers of inflammation, angiogenesis, and cartilage and bone turnover. Arthritis Rheum 2011;63:3789-800.

J Rheumatol 2013;40:1791-3; doi:10.3899/jrheum.130972

Personal non-commercial use only. The Journal of Rheumatology Copyright ( 2013. All rights reserved. 
Magnetic Resonance Imaging of Vertebral Erosion in Spondyloarthritis

Lambert RGW. Magnetic resonance imaging of vertebral erosion in spondyloarthritis. J Rheumatol 2013;40:1791-3. In reference 11 , the title should read: Vertebral erosions associated with spinal inflammation in patients with ankylosing spondylitis as identified by magnetic resonance imaging and the changes observed after 2 years of anti-TNF therapy. We regret the error.

doi:10.3899/jrheum.130972.C1 